\title{
A ASSOCIAÇÃO ECONÔMICA DOS POBRES COMO VIA DE COMBATE ÀS DESIGUALDADES ${ }^{1}$
}

\author{
Luiz. Inácio Germany Gaiger*
}

\begin{abstract}
O trabalho retoma o debate sobre as vias de resolução das desigualdades, sustentando que as iniciativas com esse fim necessitam visar à ativação econômica dos setores desfavorecidos, forma mais indicada para gerar equidade e desenvolvimento. Examina, a seguir, o modelo de ativação predominante, direcionado ao desenvolvimento das competências individuais, no qual aponta inadequações e insuficiências. Contrapõe-se um segundo modelo, de promoção do empreendedorismo em moldes associativos e, a partir dos dados do primeiro Mapeamento Nacional da Economia Solidária no Brasil, identifica-se um padrão de referência correlato. A sua análise conduz a um balanço preliminar das possibilidades de preservação e consolidação de agentes econômicos vincadas na cooperação produtiva e na autogestão.

PALAVRAS-CHAVE: cooperação, economia solidária, empreendedorismo, pobreza, tecnologias sociais.
\end{abstract}

Este trabalho tenciona contribuir com o debate sobre as vias de resolução das desigualdades, ao examinar as possibilidades de promoção econômica dos pobres por meio de sua organização em moldes associativos, com vistas à exploração coletiva dos seus recursos produtivos e dos seus ativos relacionais. A argumentação desenvolvida com esse objetivo é apresentada em três partes.

Em primeiro lugar, o texto sustenta que as iniciativas que tenham como finalidade reduzir as desigualdades necessitam conter medidas redistributivas da renda e visar à ativação econômica dos setores empobrecidos. Da literatura a respeito, conclui ser essa a forma mais indicada para gerar efeitos benéficos e duradouros sobre a equidade e sobre o desenvolvimento social e econômico.

* Doutor em Sociologia e pesquisador do CNPq. Professor e coordenador do Programa de Pós-Graduação em Ciências Sociais da Universidade do Vale do Rio dos Sinos - Unisinos. Av. Unisinos, 950 - Cristo Rei. Cep: 93022000 - Sao Leopoldo, RS - Brasil. gaiger@unisinos.

${ }^{1}$ Participam da equipe de pesquisa à raiz desse artigo: Neila Sperotto, mestre em Serviço Social, doutoranda do Programa de Pós-Graduação em Ciências Sociais da Unisinos Andressa da Silva Corrêa, graduanda em Ciências Sociais e bolsista de Iniciação Científica do CNPq.
A fim de confrontar essa linha de entendimento com seus intentos de implantação, a segunda parte do trabalho recorre à bibliografia e a dados recenseados para examinar questões suscitadas em torno de dois modelos de ação, distintos entre si como propostas de intervenção, mas ambos direcionados à ativação das capacidades produtivas dos setores economicamente desfavorecidos. De um lado, os programas convencionais de apoio ao empreendedorismo de pequeno porte, direcionados ao desenvolvimento de competências individuais, no contexto de pequenos negócios; de outro lado, a via mais recente representada pela economia solidária, com o surgimento de empreendimentos associativos e dos respectivos programas de apoio, identificados com a metodologia das tecnologias sociais.

Os argumentos apresentados questionam o conceito paradigmático de empreendedorismo de oportunidade, subjacente à maior parte dos programas convencionais, e ressaltam a presença de padrões específicos de empreendedorismo de pequena escala, que não compartilham todos os atributos da matriz schumpteriana. A compreensão e 
a promoção dos pequenos negócios requerem considerar ainda que os mercados em que se inserem os pobres estão à mercê de estruturas sociais de dominação. A vulnerabilidade dos pequenos empreendedores não decorre apenas de carências cognitivas ou da formação de competências e somente pode ser abrandada com o fortalecimento e a lenta mutação das suas atividades econômicas costumeiras, sustentadas em seus saberes práticos e em seus ativos relacionais.

Na terceira parte do texto, uma análise dos empreendimentos de economia solidária, com base nos dados do Primeiro Mapeamento da Economia Solidária no Brasil, explora-se a tese de que os ativos dos pequenos empreendedores podem ser potencializados mediante a associação dos indivíduos em cooperativas e em outras formas coletivas de produção e gestão, gerando impactos mais rápidos e sustentáveis. Ao mesmo tempo, mostra-se necessário reconhecer as dificuldades de construção da via solidária, a despeito do entusiasmo de seus estimuladores e protagonistas diretos.

A linha de entendimento desenvolvida no artigo consigna algumas aquisições parciais de um projeto de pesquisa desenvolvido em parceria entre instituições do Brasil (Unisinos), Portugal (CES - Centro de Estudos Sociais) e Moçambique (ICS - Instituto Cruzeiro do Sul). Com esses contextos nacionais de fundo, o projeto realiza um estudo internacional comparativo com o objetivo de averiguar a que ponto o empreendedorismo associativo representa um caminho promissor de criação de oportunidades de trabalho e de alternativas de produção, fomentando a participação cidadã e ensejando novas formas de intervenção social. ${ }^{2}$ Estudos aprofundados das experiências de empreendedorismo associativo, integrando-se à análise sistemática de dados representativos já disponíveis a respeito, são indispensáveis à elucidação do tema, como se sugere ao final do texto, e ao direcionamento das ações de apoio que se vêm multiplicando nesse campo.

2 A investigação desenvolve-se no âmbito do Programa de Cooperação em Ciências Sociais entre Países da Comunidade de Língua Portuguesa - CPLP, do CNPq, e conta com bolsas e auxílios dessa agência.

\section{A IMPORTÂNCIA DO PROTAGONISMO ECONÔMICO DOS POBRES}

As desigualdades constituem um dos problemas mais relevantes do Brasil e das sociedades latino-americanas que buscam avançar na consolidação de regimes democráticos, a partir de estruturas sociais profundamente injustas. Nesse contexto, desigualdades e pobreza em geral são fenômenos associados, de modo que a redução efetiva dos níveis de pobreza requer políticas e programas de combate às desigualdades. Enfrentar esse binômio representa um dos principais desafios da atualidade.

A persistência das desigualdades ao longo de nossa história indica que elas possuem raízes profundas (Sales, 1994). Uma população majoritária persistentemente de pobres, num país de recursos abundantes, tem permanecido quase imune à evolução econômica, na falta de programas estruturais contínuos, alicerçados em decisões políticas de ampla envergadura. A pobreza extrema, em particular, mantém-se presa aos processos de reiteração das desigualdades, de modo que, ao cabo de sucessivas fases de estagnação e de crescimento, o Brasil deixou de ser um país pobre e dependente, para converter-se numa das principais economias mundiais, sem deixar de conviver com um dos mais baixos índices de desenvolvimento humano.

As desigualdades econômicas, políticas e culturais formam um círculo perverso, cujo cerne mantém-se praticamente inabalado e parece recrudescer quando políticas sociais e medidas redistributivas fazem cair os seus índices passageiramente. Mesmo nas fases de evolução dos indicadores sociais, as tendências de repartição desigual da renda e de acesso diferenciado aos serviços e garantias sociais mantiveram-se constantes, pouco sensíveis ao desempenho da economia e ao acionamento de políticas compensatórias (Singer, 1999). De outra parte, a persistência da desigualdade de renda indica a força de outros poderosos mecanismos estruturais de concentração da riqueza e do poder: sejam eles as sobreposições entre as elites econômicas, políticas e sociais, seja o fato de que a riqueza 
provém, em boa medida, de relações com o Estado, como efeito de suas políticas macroeconômicas e de políticas sociais sem eficácia distributiva (Medeiros, 2005; Cattani, 2008).

A despeito da evolução do direito positivo, as desigualdades resistiram aos movimentos e às pressões sociais, reproduzindo divisões, separações e enormes desproporções no acesso de uns e outros ao bem-estar. Persistiram ainda, no plano dos valores, não obstante os avanços no reconhecimento das diferenças socioculturais. O poder instituinte das desigualdades transparece nas formas latentes de segregação, evidenciando a força inercial de atavismos banidos do quadro de direitos, ou na naturalidade com que se tolera a brutal distância social entre os brasileiros.

Nas últimas décadas, sucederam-se, no Brasil, diferentes coalizões e programas de governo, mas o país seguiu demonstrando uma enorme capacidade de resistência a mudanças em seu padrão de desenvolvimento, quer em aspectos cruciais, como a erradicação da pobreza, quer em seu espectro mais amplo, marcado pela dualização social. Desde 2001, a desigualdade de renda apresentou tendências de redução (Barros et al., 2007), embora sem garantir ainda um desfecho decisivo e animador. ${ }^{3}$ Essa nova inflexão precisaria perdurar por muito tempo, a fim de compensar a desigualdade econômica anterior, entre 1970 e 2000 (Neri, 2007), elevada e indiferente à evolução da economia, da política e dos costumes, em um país que se aproximou da maior parte das características atribuídas às sociedades modernas, exceto em seus patamares de desigualdade (Medeiros, 2005).

A superação desse quadro histórico requer a aceitação de algumas premissas em torno do problema (Gaiger; Asseburg, 2007). Em primeiro lu-

${ }^{3} \mathrm{O}$ declínio da desigualdade no país durante os anos 2000 apareceu principalmente na queda no coeficiente de Gini, que oscilou 4,6\% entre 2001 e 2005 . Tal queda relacionase ao crescimento da renda dos mais pobres, cuja fatia da renda nacional cresceu bem acima das faixas de mais altos rendimentos. Entre os fatores dessa nova inflexão na curva histórica da desigualdade de renda, estudos apontam, em primeiro lugar, a redução das diferenças entre os rendimentos do trabalho, as transferências de renda vinculadas a programas governamentais e a queda nas diferenças de remuneração por nível educacional. gar, admitir que a desigualdade não garante o crescimento econômico, e esse, por si mesmo, não produz redução da desigualdade e nivelamentos da renda, contrariamente ao apregoado pela ciência econômica há não muito tempo (Salm, 2007). O crescimento nem sempre cria condições de maior equidade, como se comprovou na América Latina nas décadas de 80 e 90, quando o crescimento registrado não chegou aos setores mais desfavorecidos para tirá-los da pobreza (Kliksberg, 2002). As reformas macroeconômicas centradas na liberação dos mercados não evitaram, nessas duas décadas, importantes incrementos da desigualdade. Sem outros meios que alterem o padrão de alta desigualdade, o crescimento não é capaz de produzir mudanças profundas na distribuição da renda e na pobreza.

Em segundo lugar, admitir que a política econômica deva estar direcionada aos setores pobres para que induza o crescimento dos mesmos e gere efeitos redistributivos diretos. Necessita estar associada a medidas redistributivas e à difusão de inovações que elevem a produtividade das atividades voltadas ao suprimento de carências que afetam a vida dos pobres (Salm, 2007). Medidas redistributivas direcionadas ao aumento da equidade produzem efeitos positivos sobre o crescimento econômico e criam circuitos virtuosos de desconcentração e crescimento (Medeiros, 2005). O equacionamento da desigualdade requer, portanto, atacar o problema da transferência de renda e da distribuição da riqueza.

Uma terceira premissa consiste em reconhecer que a erradicação da pobreza não é realizável pela via unilateral de ações governamentais, incluindo os programas de transferência de renda. Oêxito de tais programas depende das chances e dos espaços onde os afetados pelas desigualdades possam escolher o caminho para agirem na recuperação de sua dignidade e na construção de suas condições de vida. Em outras palavras, as medidas orientadas à ativação econômica dos setores sociais empobrecidos, e não apenas a melhorias em sua capacidade de consumo, são as mais indicadas para provocar efeitos benéficos sobre a equidade e o desenvolvi- 
mento social e econômico. Diferentes países confirmam a eficiência dos estímulos às pequenas unidades produtivas. As respostas obtidas, densas em investimentos, configuram, a médio prazo, uma base produtiva dinâmica que multiplica postos de trabalho. ${ }^{4}$ Investir nessa direção proporciona que os agentes econômicos mais desguarnecidos lancem mão de suas capacidades potenciais e recuperem ou formem ativos básicos, o que lhes permite organizar a vida familiar, incrementar e estabilizar seus rendimentos (Gaiger; Asseburg, 2007).

O princípio da ativação consiste em converter os beneficiários dos programas de apoio em protagonistas. Essa abordagem transfere o centro das atenções, dos mecanismos de geração e distribuição de renda, para os fatores e situações que provocam, perpetuam ou modificam diferenças nos funcionamentos das pessoas e das suas famílias (Sen, 1999).

Os funcionamentos compreendem desde aspectos básicos, como o estado de saúde e a nutrição, até aspectos subjetivos ou propriamente sociais, como o grau de felicidade, de autoestima e de participação comunitária. Importa, nessa ótica, incrementar as alternativas ao alcance das pessoas que utilizam e combinam os funcionamentos, já que isso representa a sua liberdade efetiva de optar por um tipo de vida ou outro (Sen, 2001). O mister consiste em ser um agente, alguém cuja atuação ocasiona realizações que podem ser julgadas de acordo com os valores e objetivos do sujeito da ação, supondo-se, então, ser ele capaz de definir metas próprias de bem-estar e realizá-las. De um ponto de vista não apenas econômico, devem-se fortalecer os mecanismos que transformam as capacidades em rendimentos, ensejando o desenvolvimento de funcionamentos valiosos e de novas capacidades (2001, p.79-97).

Nesse sentido, importa considerar os pa-

No Japão e na Coreia, ficou demonstrado que o estímulo às pequenas unidades produtivas gera respostas intensas de investimento nessas economias, no sentido de conter o consumo e aumentar o tempo de trabalho com vistas à poupança, melhor aproveitamento e pagamento dos créditos. Igualmente em países como Israel e Itália, o impulso à pequena e média empresa veio a constitui uma "base produtiva dinâmica geradora de emprego dirigido especialmente aos setores mais desfavorecidos." (Kliksberg, 2002, p.98). drões de privação de capacidades que afetam as pessoas. Sem superá-los, elas não reagirão adequadamente diante de oportunidades mais favoráveis, no sentido de tirar-lhes proveito, visando à melhoria de sua renda e de suas demais condições de vida, mesmo quando o desejem. Reproduz-se um círculo perverso do qual elas são vítimas e não protagonistas: pessoas sistematicamente expostas à carência, ao desemprego e à vulnerabilidade são minadas em sua autoestima e se autoexcluem da condição de agentes (Dejours, 2007). Elas necessitam de situações de reconstrução pessoal, o que requer experiências positivas de participação e reconhecimento, não apenas de recuperação de sua renda de consumo.

Numa perspectiva de mudanças estruturais de longo prazo, a ativação de indivíduos e coletividades preserva a sociedade civil como terreno primordial de luta pela introdução de novos valores e novas práticas. A ausência desses elementos converte o Estado em polo decisivo, com riscos de recuperação das demandas populares e de reversão de suas políticas. A esse respeito, Putnam (1996) advertia que a ação institucional não consegue suprir a ausência de uma comunidade cívica, fundamentada em participação e solidariedade. Deve promovê-la, se desejar evitar ou interromper ciclos viciosos estagnantes, nos quais a vida social não se referencia em estruturas próprias, mas sim no Estado e em seus aparatos, politizando-se verticalmente, na contramão do civismo (Gaiger, 2004b, p.827).

As políticas de ativação estão sujeitas a distorções e insuficiências. De um lado, há o risco de transferirem aos beneficiários a responsabilidade pelo cumprimento de suas metas. De outro, os beneficiários podem ser tentados a comportaremse de modo a continuar recebendo as vantagens a que suas carências os credenciam (Hespanha, 2005). De resto, o formato institucional da maior parte das políticas não está desenhado para estimular a melhoria das capacidades dos pobres em gerar renda e inserir-se nos mercados (Abramovay et al., 2003). As transferências públicas de renda precisam estimular a iniciativa dos beneficiários dentro 
de parâmetros realistas, no lugar de acomodá-los ou de induzi-los a assumir riscos desmedidos. Isso exige superar preconceitos contra as atividades econômicas das populações pobres e apostar em mutações progressivas, a partir de suas atividades tradicionais. Ademais, as políticas de apoio ao pequeno empreendedorismo apresentariam impacto muito mais rápido e sustentável quando articuladas a formas de organização autônomas e cooperativas, vincadas na experiência e no espírito associativo (Abramovay, 2004).

\section{UMA QUESTÃO DE MODELOS}

A promoção econômica dos pobres, através do apoio ao empreendedorismo de pequena escala, vem ganhando importância. Em certa medida, devido ao reconhecimento crescente do potencial contributo das pequenas empresas para o crescimento econômico, o emprego e a vitalidade da economia. A criação de pequenas empresas é encarada, cada vez mais, como uma modalidade de ocupação da mão de obra e como alternativa desejável à dependência dos sistemas públicos de proteção social. No tocante à informalidade, por parte dos governos existe hoje a percepção de que tais atividades desempenham um papel de adaptação às situações de crise, motivando uma avaliação menos negativa a seu respeito. Em países como Portugal, procura-se conferir alguma proteção ao setor informal, na direção igualmente observada no Brasil, de reconhecimento dessas iniciativas e de estímulos para que se formalizem e se mantenham legalizadas (Portela et al., 2008).

Entretanto, a severidade da concorrência imposta pelo mercado, aliada à fragilidade interna dos pequenos negócios, vem conduzindo a resultados parciais ou a fracassos das políticas do setor, como atestam as altas taxas de mortalidade das micro e pequenas empresas ${ }^{5}$ a magnitude persis-

${ }^{5}$ Ao redor de $52 \%$ delas fecham nos dois primeiros anos e têm características de economia local (Disponível: www.sebrae.com.br/customizado/estudos-e-pesquisas/ estudos-e-pesquisas/empreendedorismo-no-brasil-pesquisa-gem. Acesso em: 23 abr. 2008). tente do setor informal. A questão é particularmente aguda em sociedades onde proliferam formas de produção menos ligadas ao mercado, movidas por uma racionalidade econômica não-lucrativa e desenvolvidas por pessoas com recursos limitados, como é o caso de boa parte das sociedades sul-europeias e da absoluta maioria dos países latino-americanos e africanos. A insuficiência e descontinuidade dos apoios econômico-financeiros, ou daqueles ligados à qualificação da atividade produtiva, sem dúvida, comprometem os resultados. Um problema substantivo reside no fato de que muitos negócios criados por indivíduos isolados, ou por pequenos coletivos, não obedecem aos requisitos clássicos do comportamento empreendedor veiculado nesses programas, tais como a assunção do risco, a desenvoltura na gestão, a disposição à mudança, a busca de oportunidades e a criação de valor.

Os agentes econômicos de pequena escala movem-se, em geral, por um empreendedorismo de necessidade (Ferrão et al., 2005): na ausência de oportunidades de emprego por conta de outrem, ou pelo menos de postos de trabalho com características adequadas às suas competências específicas, esses indivíduos optam pelo trabalho por conta própria ou por arranjos coletivos, como pequenos grupos ou associações, quando lhes são oferecidas tais opções. Embora almejem rendimentos mínimos, as iniciativas de pequena escala representam uma escolha racional e não ficam, por conta disso, condenadas ao nível da subsistência. Elas guardam uma capacidade empreendedora potencial, a ser explorada a partir dos saberes e da criatividade legados pela experiência econômica dos pobres (Abramovay, 2004) e conduzida a formar atitudes de inovação e de eficiência (Gaiger, 2006). Apesar de precárias, essas atividades habilitariam os seus promotores a operar com razoável grau de flexibilidade, familiarizando-os com o negócio em seus componentes de organização e de mercados, diante dos quais alcançam amiúde uma relação estável, mesmo se minimamente lucrativa. Embora sejam inicialmente avessas às características convencionais do empreendedorismo, essas modalidades poderiam evoluir para esse modelo 
ou criar um ambiente mais favorável à disseminação de uma lógica empreendedora, adaptada às suas circunstâncias singulares.

De todo o modo, existe um reconhecimento cada vez maior do papel das pequenas unidades econômicas, como fontes de trabalho e como elementos dinâmicos do desenvolvimento. O empreendedorismo já não é visto como um traço peculiar típico das grandes empresas, inclusive no que se relaciona à capacidade de inovação, que estaria crescendo em empresas menores desde o Pós-guerra (Portela et al., 2008). Contudo, paradoxalmente, os arranjos autônomos e associativos de produção de bens e serviços, como aqueles que se perfilam sob a economia solidária, têm merecido uma atenção inexpressiva. Salvo exceções muito recentes, ficam relegados a uma posição secundária e subalterna nas políticas voltadas ao empreendedorismo de pequeno porte e na compreensão vigente a respeito. Geralmente, as iniciativas de apoio a esse campo ou se restringem às organizações maiores, notoriamente as grandes e médias cooperativas, ou desconsideram as especificidades essenciais dos empreendimentos associativos e os tratam como empresas convencionais de capital privado.

A larga predominância dos modelos centrados nos aspectos individuais do comportamento empreendedor cria obstáculos ao desenvolvimento de outras concepções e práticas. É o caso evidente dos programas usuais de apoio ao empreendedorismo de pequeno porte no Brasil, cuja excelência é reconhecida nas ações de suporte e formação do Serviço Brasileiro de Apoio às Micro e Pequenas Empresas (SEBRAE), instituído em 1972. (Passos et al., 2008). Essa mesma entidade se tem encarregado de perscrutar a realidade da economia informal e das micro e pequenas empresas no Brasil, constatando a penúria e a enorme fragilidade desses negócios, cuja desfecho mais comum é o encerramento das atividades em breve espaço de tempo. ${ }^{6}$ Os dados demonstram a insufi-

${ }^{6}$ Entre outros documentos, ver: Empreendedorismo no Brasil, do Global Entrepreneurship Monitor - GEM e Instituto Brasileiro de Qualidade e Produtividade - IBQP, 2007; Fatores condicionantes e taxa de mortalidade dasmicro e pequenas empresas, do Vox Populi e SEBRAE, 2007. ciência das ações de apoio, que obviamente estão longe de atingir a massa de potenciais microempreendedores, mas não parecem colocar em xeque o modelo de fomento, prodigalizado repetidamente ao seu público-alvo e à opinião pública em geral. ${ }^{7}$

É perfeitamente aceitável que o empreendedorismo seja visto e promovido com foco no estilo de comportamento de indivíduos. Se, em determinada organização econômica, ninguém demonstra competências empreendedoras, será impossível encontrá-las no coletivo. Esse nível de percepção faz muito sentido no caso das organizações econômicas sob comando de um ou de poucos indivíduos, onde cabe aos demais um papel secundário. Por isso, na concepção hoje em voga, a noção de empreendedorismo "não é vista como um processo, mas como um mosaico de características de indivíduos agindo racional e intencionalmente", acentuando-se o papel do ator individual (Portela et al., 2008, p.45).

No entanto, a ênfase quase exclusiva dada aos indivíduos pelas políticas tradicionais de apoio ao empreendedorismo explica-se menos pela prática e mais pelo viés ideológico que afeta essas concepções, de par com um desconhecimento da economia dos setores populares, na qual predominam os negócios por conta própria e grassa a informalidade.

O problema do viés relaciona-se, em suma, ao mito do empreendedor: o êxito do líder dos negócios seria garantido pelo seu espírito de iniciativa, talento e persistência, fatos supostamente confirmados por inúmeras histórias de sucesso. Uma análise dos documentos que dão suporte à atuação do SEBRAE ou que procuram sublinhar os seus princípios básicos deixa transparecer rapidamente as seguintes noções: ${ }^{8}$

- O empreendedor é um indivíduo de personalidade e talento, que preenche um padrão determinado, o que lhe confere sucesso econômico, pres-

7 Para um exame das publicações do SEBRAE ou a ele favoráveis, consultar www.biblioteca.sebrae.com.br.

${ }^{3}$ Após ampla consulta, foi examinado seletivamente um corpus de 15 textos, de autoria de técnicos do SEBRAE, analistas, consultores externos e acadêmicos. 
tígio e chances crescentes de novas realizações.

- Entre outras características superiores do empreendedor, destaca-se a capacidade de perceber oportunidades de negócios que outros não percebem e de inovar em um ou vários planos (tecnologia, formas de produção, mercados, matérias-primas, etc.).

- O empreendedor tem iniciativa, corre riscos calculados, cobra eficiência e qualidade, mostra persistência e comprometimento, é devotado ao trabalho, dispõe de uma rede de contatos, planeja e estabelece metas, é persuasivo, autoconfiante e independente.

O empreendedor maneja essa plêiade de virtudes otimizando as suas escolhas racionalmente e maximizando sua utilidade individual. Em face da ação empreendedora por necessidade, muito mais comum entre os pequenos negócios, o empreendedor por oportunidade é o tipo ideal a ser atingido, posto que, ao se tratar de uma opção escolhida, o ato de empreender contará com maior persistência e segurança por parte do agente econômico (Passos et al., 2008, p.11).

A partir dos anos 80, com o avanço das diretivas e políticas neoliberais, passaram a imperar propostas de criação não mais de empregos, mas de autoempregos, através da montagem de empreendimentos pelos desempregados, como "empresários de si mesmos". Conforme Kraychete, "De um paradigma antropológico do indivíduo-máquina passa-se, agora, a uma nova matriz: aquela do indivíduo-empresa” (2000, p.24). Ora, desfazendo o mito construído pela teoria econômica e pelo discurso social, é possível demonstrar que o sucesso empreendedor é, antes de tudo, uma obra coletiva que demanda capital social prévio e relacionamentos privilegiados (Boutillier; Uzunidis, 1999).

Uma barreira de desconhecimento caracteriza o senso comum acerca das ocupações típicas da informalidade, percebidas unilateralmente como situações determinadas por um alto grau de carência e despreparo, cuja superação demandaria que fossem convertidas em pequenas empresas. Nestas, caberia suplantar os traços pouco inovadores e o comportamento tradicional, que entravam o desenvolvimento a ser proporcionado pela entrada no mercado globalizado. Usual entre as agências multilaterais de cooperação ao desenvolvimento, a idéia da formalização do informal e de modernização das PMEs deu à luz muitos programas de apoio técnico e de microcrédito, entre outros, com resultados globais modestos e discutíveis (Lautier, 2005). A razão principal está em que atribuem às pequenas empresas semifamiliares uma lógica que lhes é estranha, pois não são, simplesmente, empresas capitalistas pequeninas ou ineficientes, mas uma "extensão da unidade doméstica”, na qual o objetivo de acumulação é condicionado àqueles de "manter e melhorar a qualidade de vida”, o que torna inseparáveis a produção e a reprodução (Coraggio, 2000, p.96-97).

É um equívoco, portanto, conceber o empreendedorismo estritamente no plano individual. Mesmo nas empresas privadas de comando centralizado, a mentalidade e as condutas empreendedoras precisam disseminar-se na corporação, ser parte do ambiente organizacional, motivando a cooperação e o zelo de todos. A formação de uma cultura coletiva na empresa, impessoal e já não individualizável, supõe interações constantes, ensejando a socialização de informações e conhecimentos provenientes dos diferentes indivíduos que a integram (Sainsalieu; Kirschner, 2006). ${ }^{9}$ No segmento dos pequenos negócios, nos quais abundam as iniciativas de formação de novos empreendedores individuais, o mesmo valerá à medida que a empresa crescer e se tornar mais complexa, como resultado da ação empreendedora inicial. Esta, contudo, dependerá, desde o primeiro momento, do sucesso dos relacionamentos com todos os parceiros do negócio (em certa medida, também com os concorrentes), que precisam ser motivados a engajarem-se em uma determinada estratégia de ação. ${ }^{10}$

Com mais forte razão, isso vale para os empreendimentos associativos, em que o patrimônio, o poder e as responsabilidades são partilhados. $\mathrm{O}$

${ }^{9}$ Para uma revisão no campo da sociologia das empresas no Brasil, ver igualmente Kirschner (2003).

${ }^{10}$ Não é à toa que os depoimentos sobre "casos de sucesso" destacam com frequência a importância de se encontrarem "parceiros que pensam como a gente". 
foco de atenção desloca-se, aqui, do estamento líder da organização, para a análise das correspondências entre a mentalidade empreendedora da liderança e a mentalidade do conjunto de trabalhadores. Importaria então, nesses casos, examinar o padrão empreendedor do coletivo de trabalhadores e o seu grau de homogeneidade e coesão.

\section{O EMPREENDEDORISMO ASSOCIATIVO}

A menor atenção concedida aos aspectos supraindividuais do comportamento empreendedor teve como uma das suas principais exceções a literatura consagrada ao cooperativismo. Nos dias atuais, com a visibilidade adquirida pela economia solidária, é de se esperar o surgimento de novas contribuições dos estudos a respeito.

O conceito de economia solidária reveste-se de uma conotação política e normativa, inerente à sua construção como realidade social ainda em curso. Abstraindo-se momentaneamente essas dimensões, pode-se dizer que o termo refere-se a práticas econômicas de iniciativa de pessoas livremente associadas, com algumas características básicas: algum grau de socialização dos meios de produção; dispositivos de cooperação no trabalho; elementos de gestão democrática; envolvimentos em ações mais amplas, a partir do entorno dos empreendimentos (Gaiger; Laville, 2009).

O caráter dessas práticas tem sido analisado em vários países da América Latina (Coraggio, 2007) e da periferia mundial (Santos, 2002). Desde os primeiros desenvolvimentos teóricos (Razeto, 1997), a dimensão empreendedora dessas organizações é enfatizada como marca diferencial das formas costumeiras de gestão da economia popular. O empreendedorismo associativo, ao acionar fatores produtivos advindos da cooperação no trabalho e da participação, fazendo frente a elementos contrapostos à eficiência dos formatos coletivos a exemplo dos custos de transação - favoreceria a sobrevivência e a consolidação dessas iniciativas, reforçando, ao mesmo tempo, sua dimensão social, inerente ao fato de constituírem sociedades pri- mordialmente de pessoas (Gaiger, 2004a).

Tendo em vista as características associativas e as práticas de autogestão que unificam essas experiências conceitualmente (e as unem, politicamente), é razoável considerar que elas favoreçam a verificação empírica e o desenvolvimento conceitual do empreendedorismo segundo uma ótica sensível às suas dimensões relacionais. Essa tarefa, a que se dedica o texto doravante, requer previamente algumas decisões metodológicas, desdobradas a seguir em constatações preliminares que, por sua vez, ao final, indicarão tópicos para uma agenda mais aprofundada de investigação.

\section{Micro e pequenos empreendimentos asso- ciativos: uma delimitação metodológica}

Até há pouco tempo, a inexistência de informações abrangentes e sistematizadas sobre a economia solidária conduziu as pesquisas empíricas a concentrarem-se em estudos de caso ou de setores específicos. ${ }^{11}$ Embora valiosa para o exame de situações particulares, essa abordagem qualitativa não é suficiente para aquilatar as tendências predominantes dos empreendimentos de economia solidária, os seus efeitos sobre a vida dos trabalhadores e a eficácia comparativa das estratégias de apoio aos empreendimentos. A situação alterou-se em fins de 2007, uma vez que as pesquisas passaram a contar com a base de dados oriunda do primeiro Mapeamento Nacional da Economia Solidária no Brasil, integrada ao Sistema Nacional de Informações sobre a Economia Solidária (SIES). Esse Sistema resulta de um trabalho conjugado do poder público (SENAES/ MTE), dos fóruns representativos dos empreendedores solidários e de organizações de apoio. Entre 2003 e 2007, o Mapeamento mobilizou mais de 230 entidades e a ida a campo de 600 técnicos e entrevistadores.

${ }^{11}$ Ver, por exemplo, as compilações de Singer e Souza (2000), ou de Martins e Medeiros (2003), além dos artigos reunidos em Laville et al. (2005). Ressaltem-se ainda alguns estudos comparativos, embora setoriais, como Peixoto e Lopes (1999), Lima (2004) e Piccinini (2004). 
OMapeamento equivale tecnicamente a um levantamento amplo de informações, não a um censo ou a uma pesquisa amostral. Ainda assim, como agrega informações sobre 22 mil empreendimentos, distribuídos em 2.274 municípios, nas 27 Unidades da Federação, a base de dados do SIES pode ser considerada representativa das iniciativas da economia solidária. As informações coletadas compreendem as condições de formação dos empreendimentos, suas estratégias de desenvolvimento e os benefícios que aportam para seus integrantes e seus entornos sociais. O SIES oferece uma referência empírica propícia ao uso dos recursos da análise quantitativa e à discussão de hipóteses a partir de uma visão ampla do perfil socioeconômico e das formas de gestão dos empreendimentos. Antes de serem colocados a público, os dados sofreram um processo de retificação, por meio de testes de consistência. Dentro de patamares razoáveis de confiabilidade, a base de dados foi validada. ${ }^{12}$

Para os propósitos desse artigo, uma providência importante consistiu em comparar as características dos empreendimentos econômicos solidários (EES), utilizadas para definir o escopo do Mapeamento, com as informações prestadas pelas organizações atingidas pelo trabalho de coleta. Para serem consideradas como EES, as iniciativas econômicas deviam satisfazer cinco requisitos: a) constituírem organizações suprafamiliares permanentes; b) sob propriedade ou controle dos sócios-trabalhadores; c) com emprego ocasional e minoritário de trabalhadores não-associados; d) com gestão coletiva das suas atividades e da alocação dos resultados; e) de natureza econômica, direcionada à produção, comercialização, serviços, crédito ou consumo. Após uma bateria de testes com a finalidade de identificar as organizações em desacordo com esses parâmetros, o perfil dos EES mostrou-se satisfatório: há organizações frágeis economicamente ou no tocante a práticas de autogestão; porém, como todas

${ }_{12}$ A base conceitual, a metodologia e a avaliação dos procedimentos utilizados no Mapeamento constam do Atlas da Economia Solidária no Brasil e de documentos disponíveis em: www.sies.mte.gov.br. O tratamento dos dados foi coordenado pela Unisinos e pelo IPEA. as frações referentes aos EES em situação contraditória com o conceito de economia solidária são inferiores a $1,5 \%$, pôde-se concluir que o SIES, salvo tais exceções, registra experiências econômicas de natureza associativa.

O porte dos EES, as formas de organização adotadas e os setores econômicos nos quais atuam são variados. Para uma caracterização muito breve: $51,8 \%$ dos EES são associações, 36,5\%, grupos informais e 9,7\%, cooperativas. As atividades coletivas mais comuns são a produção $(63,3 \%)$, a comercialização (59,6\%) e o uso de equipamentos produtivos (49,9\%). A fisionomia rural da economia solidária é visível, uma vez que 54,9\% dos EES dedicam-se à agricultura, pecuária, pesca ou extrativismo, os demais se repartindo entre a produção e a prestação de serviços em setores de alimentação, confecções e calçados, artesanato, indústria de transformação, coleta e reciclagem e, ainda, crédito e finanças.

Quanto ao porte, 24\% dos EES possuem até 30 sócios, enquanto, no extremo oposto, registram-se 370 casos $(1,7 \%)$ com mais de 500 associados. Ao redor de 19,7\% dos EES possuem menos de 6 sócios trabalhando regularmente no empreendimento e 59,3\% possuem até 30 trabalhadores dentro do seu quadro social. Já ao se contabilizarem unicamente os trabalhadores nãosócios, 70,8\% dos empreendimentos que os empregam (14,9\% do total) possuem até 5 trabalhadores e apenas $5,4 \%$ possuem mais de 30 trabalhadores não-sócios. Predominam as faixas de 6 a 15, para os trabalhadores sócios, e de 1 a 5 , para os trabalhadores não-sócios.

Para que o SIES servisse adequadamente à análise de situações de microempreendedorismo associativo comparáveis àquelas do microempreendedorismo individual, delimitou-se um subconjunto de EES com as seguintes características: a) atividades econômicas principais relacionadas à produção, prestação de serviços, comercialização, aquisição de matérias-primas e insumos ou obtenção de clientes e serviços para os sócios; b) empregando de 1 a 30 trabalhadores, contados sócios e não-sócios; ${ }^{13} \mathrm{c}$ ) em funcionamen- 
to normal, excluindo-se os EES em "fase de implantação”. A aplicação desses critérios resultou na seleção de 10.625 organizações (48,6\% do total), designadas de MPEA - Micro e Pequenos Empreendimentos Associativos.

Os MPEA possuem algumas peculiaridades, quando comparados aos EES em geral:

- Apresentam frequências mais elevadas na metade sul do país (exceção ao Piauí), com destaque para a região Sudeste, que abarca 24,8\% deles.

- Sua localização e área de atuação econômica são principalmente urbanas (63,4\%), às vezes envolvendo igualmente o espaço rural (17,3\%).

- Concentram suas atividades em setores relacionados à indústria de transformação (50,8\%), seguida da agricultura e pecuária (31,1\%), de acordo com a CNAE. Quanto aos produtos e serviços, prevalecem ramos tradicionais, principalmente artesanato $(22,4 \%)$, alimentos e bebidas $(17,8 \%)$, têxteis e confecções $(13,2 \%)$, dentro de uma gama variada que se estende até os serviços de coleta e triagem de recicláveis (2,8\%).

- São majoritariamente recentes: as atividades econômicas de 55\% deles tiveram início a partir de 2001. Ao redor de 17\% iniciaram as atividades após 2004. Dado o período de realização do Mapeamento, muitos empreendimentos haviam superado recentemente a fase inicial de implantação quando houve a coleta de dados. Cabe salientar, por outro lado, que 35,5\% dos MPEA datam dos anos 1990 e que 9,3\% deles são ainda mais antigos. Quando o Mapeamento teve início, 44,8\% dos MPEA já funcionavam há pelo menos 5 anos. ${ }^{14}$

- Entre as razões alegadas para justificar o início das atividades, despontam aquelas relacionadas à busca de opções ao desemprego e à geração complementar de renda, diminuindo a procura de recursos oferecidos exclusivamente a grupos

${ }^{13}$ Como a pluriatividade é regra entre os EES, essa delimitação intermediária quanto ao porte buscou aproximá-los do universo das MPE usual nas pesquisas do IBGE e nos estudos e ações do SEBRAE. No caso das microempresas, até 9 (comércio e serviços) ou 19 (indústria e construção) trabalhadores; no caso das pequenas empresas, de 10 a 49 e de 20 a 99 trabalhadores, respectivamente.

${ }^{14} \mathrm{Um}$ bom indicador de longevidade, considerando as taxas de mortalidade das MPE. ou entidades (motivação comum entre produtores familiares) e o intuito de promover o desenvolvimento comunitário. Trabalho e geração de renda caracterizam os MPEA.

- Quase a metade (49\%) desses empreendimentos é informal. O seu registro como associações ocorre em $39 \%$ dos casos, enquanto as cooperativas abrangem 9,5\%. Uma fatia menor, de $2,3 \%$, corresponde a sociedades mercantis e outras formas. As altas taxas de informalidade denotam o caráter recente e precário dos MPEA, uma vez que se encontram desprovidos das condições plenas de atuação econômica. Em certa medida, o mesmo vale para as associações. ${ }^{15}$ De outra parte, observa-se, entre os MPEA, um segmento de pequenas cooperativas (1.014 casos), menores do que as associações e maiores do que os grupos informais. Como esses últimos, as cooperativas são predominantemente urbanas.

\section{Um padrão empreendedor de referência}

As informações atualmente disponíveis no SIES não permitem uma análise em pormenores dos padrões em que se apresenta o microempreendedorismo associativo, o que provavelmente será viável com os dados bem mais detalhados a serem coletados no segundo Mapeamento da Economia Solidária, em 2009. Nesse momento, é possível examinar alguns aspectos gerais, com o fim de obter algumas sinalizações preliminares a respeito. Esses primeiros resultados têm a virtude de colocar à prova as hipóteses deste estudo, quanto à pertinência de uma abordagem teórico-conceitual sobre o microempreendedorismo que valorize os seus aspectos relacionais e associativos e quanto ao fato de que, a julgar pelo desempenho dos MPEA registrados no SIES, tenha sentido estimálos como uma via razoavelmente promissora de

${ }^{15}$ Entre os EES, em geral, as associações predominam $(51,8 \%)$ e se relacionam muitas vezes à busca de benefícios para a atividade econômica individual dos associados, não implicando, assim, uma atividade produtiva específica do empreendimento e o envolvimento de trabalhadores. 
combate às desigualdades.

A primeira questão examinada diz respeito à existência de uma fração dos MPEA dotada de um desempenho econômico apreciável e de características a ele vinculadas que componham o que poderíamos chamar de um padrão empreendedor de referência. $\mathrm{O}$ ponto de partida da análise a esse respeito foi a variável que dividia os empreendimentos segundo os resultados econômicos globais de sua atividade no ano anterior ao Mapeamento. O que resulta nas seguintes informações:

extrafinanceiras. As conclusões são as seguintes:

- O resultado econômico-financeiro globalmente positivo de alguns MPEA apresenta-se associado com nitidez a outras características de bom desempenho econômico: adimplência creditícia; facilidade de obtenção de crédito; menor necessidade de crédito; direcionamento preferencial dos recursos excedentes para investimentos; maior volume de produção e faturamento; existência de sócios trabalhadores com remuneração regular.

- Outras característi-

Tabela 1 - Resultados da atividade econômica do empreendimento no ano anterior (sem contar as doações. caso existam)

\begin{tabular}{l|c|c|c|c}
\hline Resultados finais no ano anterior & Frequência & Percentual & $\begin{array}{c}\text { Percentu- } \\
\text { al válido }\end{array}$ & $\begin{array}{c}\text { Percentual } \\
\text { cumulativo }\end{array}$ \\
\hline $\begin{array}{l}\text { Pagar as despesas e ter uma sobra ou } \\
\text { excedente }\end{array}$ & 4.833 & 45,5 & 45,6 & 45,6 \\
\hline $\begin{array}{l}\text { Pagar as despesas e não ter nenhuma } \\
\text { sobra }\end{array}$ & 3.560 & 33,5 & 33,6 & 79,3 \\
\hline Não deu para pagar as despesas & 1.397 & 13,1 & 13,2 & 92,5 \\
\hline $\begin{array}{l}\text { Não se aplica (para empreendimentos } \\
\text { que não visam a esse tipo de resultado) }\end{array}$ & 799 & 7,5 & 7,5 & 100,0 \\
\hline Total & 10.589 & 99,7 & 100,0 & \\
\hline Missing System & 36 & 0,3 & & \\
\hline Total & 10.625 & 100,0 & & \\
\hline
\end{tabular}

uma relação tênue, embora coerente com esse padrão econômico superior: faixas de remuneração dos trabalhadores mais elevadas; menor utilização de trabalho voluntário ou de contrapartidas em espécie (autoconsumo); práticas de qualificação social e profissional dos sóci-

O percentual de empreendimentos que concluíram o ano com resultados positivos é maior entre os MPEA (45,6\%) do que no conjunto geral de EES (38,3\%), sendo ademais considerável. Há também pequenos incrementos nos extratos inferiores, com ligeira diminuição do número de empreendimentos que não lograram arcar com todos os seus compromissos financeiros. Isso posto, uma bateria de cruzamentos foi realizada no sentido de verificar se há outros indicadores de boa saúde financeira que acompanham o extrato superior, conferindo-lhe consistência, e se há circunstâncias que caracterizam e explicam as diferenças entre os extratos. A análise incidiu em cinco pontos: a) o capital inicial dos MPEA (material, financeiro e humano); b) o volume da atividade econômica; c) a captação de crédito e a presença de investimentos; d) o perfil da atuação no mercado; e) as retribuições aos trabalhadores dos MPEA, financeiras e os; produção integralmente destinada ao mercado e maior amplitude deste; obtenção de crédito e realização de investimentos nos últimos 12 meses.

- Há fatores sem incidência aparente sobre o desempenho econômico: todos aqueles relacionados ao capital do empreendimento (origem e propriedade dos recursos iniciais, dos equipamentos e da sede, além da evolução posterior do quadro social); os valores dos créditos obtidos e dos investimentos realizados; o número (geralmente pequeno) de trabalhadores não-sócios.

Embora a influência diferencial desses diversos elementos mereça um estudo minucioso, de acordo com os dados disponíveis, a noção de um padrão empreendedor de referência se sustenta. Ou seja, os MPEA situados no extrato superior representariam casos de conjunção bem sucedida de circunstâncias e de estratégias favoráveis à sua 
viabilidade e reprodução, que redundam em bom desempenho econômico. Como veremos adiante, o êxito nesse aspecto não é dissociável de aspectos relativos ao modelo de gestão, em termos de participação e descentralização do poder decisório.

Determinados fatores apresentam um comportamento singular em relação aos três extratos indicados na tabela acima, uma vez que não seguem uma tendência linear ascendente ou descendente. Assim, os MPEA do primeiro extrato, embora tenham volumes médios de atividade econômica e de faturamento claramente superiores aos demais, não empregam um número médio de trabalhadores maior. Tampouco haviam realizado (nos últimos 12 meses) investimentos mais vultosos ou contraído créditos na proporção da sua maior capacidade produtiva. Por serem menos recentes do que os demais MPEA, é possível imaginar que já houvessem superado as necessidades mais prementes de investimento ou de financiamento do seu capital de giro.

Entretanto, os dados sugerem igualmente que tais MPEA acabaram por adotar um modelo austero de gestão: eles teriam ajustado sua força de trabalho às necessidades reais, quiçá buscando ganhos em produtividade; em geral, abdicaram de remunerações mais elevadas, acima de cinco salários-mínimos; optaram por não ampliar o número de sócios, ao menos no último ano; contraíram créditos com parcimônia, da mesma forma que administraram os seus investimentos. Haveria, de sua parte, uma gestão cautelosa, ponderando-se os riscos, para garantir a sobrevivência do empreendimento.

No extremo oposto, entre os MPEA que fecharam o ano sem conseguir pagar as despesas, determinadas características chamam a atenção, ainda que não sejam predominantes. Elas se referem a subgrupos diferentes do extrato e podem revelar situações distintas do ponto de vista do comportamento empreendedor. Algumas sugerem uma gestão ousada, calculada, com base no senso de oportunidade:

- Mercados principais visados de amplitude estadual ou nacional.

- Valor médio de investimentos superior aos de- mais extratos.

- Valores médios de faturamento e de créditos obtidos superiores ao segundo extrato.

- Proporção maior de trabalhadores não-sócios com vínculo formal, mediante contrato permanente ou por prestação de serviços.

Outras características apontariam a presença de uma gestão temerária, seja por idealismo ou inexperiência, seja por imposição das necessidades:

- Impossibilidade mais frequente de remunerar regularmente os trabalhadores.

- Média de remuneração dos trabalhadores sócios superior ao segundo extrato.

- Média de remuneração dos trabalhadores nãosócios superior aos demais extratos.

- Casos proporcionalmente consideráveis de remuneração nas faixas acima de 5 salários-mínimos.

Apenas um maior adentramento nos dados, aliado a pesquisas qualitativas sobre esses casos, poderia elucidar exatamente de que se trata. Em todo o caso, fica consignada a provável existência de diferentes padrões de empreendedorismo, bem como a presumível insuficiência de senso empreendedor em determinadas circunstâncias. $\mathrm{O}$ fato de que 45,6\% dos MPEA estejam situados no primeiro extrato, capaz de gerar excedentes e dotado de outros indicadores de desempenho econômico, ao que se acresce que 45\% dos mesmos MPEA já funcionavam ao menos há cinco anos, reforça a tese de existência de um padrão empreendedor no interior dessas organizações econômicas associativas.

Uma segunda questão examinada concerne precisamente à influência exercida pelas práticas de autogestão dos MPEA sobre o seu desempenho econômico. Essa relação entre a dimensão democrática e participativa dos empreendimentos e a sua eficiência econômica é essencial na abordagem teórica aqui proposta. Ela já foi objeto de uma análise anterior do SIES, com resultados globalmente positivos:

os dados sugerem que o conjunto de EES obedece a uma relação positiva entre maior solidarismo e maior empreendedorismo: a cada grau de empreendedorismo corresponde um grau proporcionalmente maior de solidarismo. Os casos de desenvolvimento unilateral seriam minoritários (Gaiger, 2007, p.69). 
O fato condiz com estudos qualitativos anteriores, segundo os quais o desenvolvimento da dimensão empreendedora não inibiria a autogestão e o engajamento social das organizações, sendo suscetível de estimulá-los ou mesmo de pressupôlos (Gaiger, 2006).

A análise preliminar do subconjunto formado pelos MPEA não contradiz essas conclusões, mas tampouco as confirma taxativamente. A maior parte dos empreendimentos dispõe deinstâncias colegiadas de direção, admite a participação dos sócios por meio de diversos instrumentos e promove reuniões deliberativas periodicamente. Não há diferenças nítidas a ponto de demarcarem modelos mais ou menos autogestionários, em correspondência com níveis de desempenho econômico distintos.

Os MPEA situados no padrão empreendedor de referência despontam discretamente em mecanismos de gestão participativa que podem denotar uma condução autogestionária com certa maturidade: de um lado, a definição de planos de trabalho em assembleia ou reunião geral, da mesma forma que as decisões sobre o destino das sobras e fundos; de outro lado, a adoção de grupos, comissões ou núcleos de trabalho, aliada à participação dos sócios nas decisões cotidianas do empreendimento.

Por sua vez, os MPEA que acusaram resultados econômicos negativos tomam a dianteira sobre o extrato intermediário em alguns quesitos. Destaca-se o fato de propiciarem aos sócios o acesso a registros e informações e de prestarem contas em assembléia ou reunião geral. Em maior proporção, eles contam com instâncias coletivas de direção e com instrumentos de controle, a exemplo do conselho fiscal. Sendo relativamente mais jovens do que os demais, poderiam estar imbuídos do elã participativo e democrático que caracteriza o ambiente social e político da economia solidária nos últimos anos.

Por conseguinte, se a autogestão não aparece como um elemento diferencial, de resto porque se apresenta disseminada horizontalmente, tampouco há motivos para considerá-la um óbice ou um elemento secundário, extrínseco à identi- dade peculiar e ao modo de gestão dos MPEA. Nas condições adversas em que operam os empreendimentos, lutando em primeiro lugar contra desafios de curto prazo, é provável que outros fatores objetivos e subjetivos se interponham e selem as chances de êxito econômico, a despeito do grau de autogestão verificado.

\section{O fomento ao microempreendedorismo associativo}

Para que os empreendimentos associativos não se circunscrevam a iniciativas momentâneas e isoladas, necessitam dotar-se de instrumentos de orientação e de linhas propulsoras confluentes, que produzam efeitos de integração horizontal e vertical. Quando se localizam em ambientes pródigos em articulações e em apoios externos, essas vantagens podem ser decisivas (Gaiger, 2004a), sobretudo após ultrapassarem os momentos iniciais de idealismo ou de pressões mais severas decorrentes da ausência de alternativas de trabalho. Esses processos de qualificação, mobilização e politização não têm ocorrido na economia solidária, como em geral não ocorrem nos setores populares, sem a presença de agentes externos de mediação. ${ }^{16}$ Voltamos, então, ao tema dos modelos de fomento direcionados aos pequenos empreendedores.

O método de intervenção das entidades de apoio termina por conferir uma fisionomia singular ao segmento da economia solidária visado por sua ação, do ponto de vista da identidade e das estratégias de relacionamento e participação política dos EES (Gaiger, 2005). Os dados gerais do SIES confirmam a presença dessas externalidades: $72,7 \%$ dos empreendimentos declararam ter recebido apoio ou assessoria externa, 40,6\% de órgãos governamentais, $22,9 \%$ de ONGs, Igrejas ou asso-

${ }^{16}$ Agentes mediadores são os indivíduos, detentores de uma competência técnica ou política, que se engajam num dado campo de ação social, a partir de um quadro institucional (ONGs, etc.) e segundo as finalidades e diretivas deste, ficando o seu papel de intermediação legitimado pela eficácia que demonstram em aportar instrumentos ao ator popular ou em favorecer que atinja seus objetivos. 
ciações e $11,5 \%$ do movimento sindical. ${ }^{17}$ Cabe destacar que o "Sistema S", no qual se inclui o SEBRAE, foi citado por 20,4\% dos EES. Os MPEA não diferem dessa realidade, pois 74,3\% afirmaram ter recebido algum tipo de apoio, sendo o percentual levemente superior entre os MPEA de maior desenvoltura econômica.

O exame dos dados gerais sobre a totalidade dos EES demonstra que aqueles beneficiados com algum apoio apresentam um grau de desempenho global mais positivo do que os demais, exceto no caso de EES apoiados unicamente por órgãos governamentais (Gaiger, 2007). Além disso, modalidades a princípio mais convencionais e padronizadas de apoio (qualificação profissional, técnica ou gerencial) ou voltadas a um objetivo momentâneo (assessoria na constituição e legalização dos EES) não parecem surtir maiores efeitos. Já as assessorias de formação sociopolítica ou que incidem sobre gargalos conhecidos dos empreendimentos (assistência jurídica, comercialização e planejamento) provocariam melhores resultados.

A mesma análise revela que a origem institucional do apoio faz diferença. Do ponto de vista exclusivo do desempenho econômico, o impacto diferencial positivo é causado, de maior a menor, por universidades e incubadoras, Sistema S e cooperativas de técnicos. Considerando-se os efeitos sobre o desenvolvimento global - econômico, social e político - dos EES, algumas posições se invertem: as cooperativas de técnicos e o movimento sindical passam à dianteira, seguidos pelas universidades e incubadoras, enquanto o Sistema S e os órgãos governamentais assumem as últimas colocações.

As feições institucionais das entidades de apoio, com seus componentes históricos, políticos e metodológicos, repercutem sobre o seu público-alvo. De acordo com a compreensão - ou mais orientada ao econômico ou mais integral - que se tenha dos empreendimentos associativos, as preferências se

${ }^{17} \mathrm{Na}$ base parcial de dados de 2005, foram identificadas 1.120 entidades de apoio, das quais $87 \%$ de atuação loca e $10 \%$ com abrangência nacional, destacando-se ONGs (46\%) e entidades confessionais (24\%). modificam. Um fato que se reveste de interesse, caso for possível identificar, em cada segmento institucional, é a existência de modelos (latentes ou patentes) de promoção do empreendedorismo de pequeno porte, quer se assemelhem à concepção predominante centrada nos indivíduos e transposta à realidade dos MPEA, quer assumam outras premissas, enfatizando os aspectos relacionais desses empreendimentos.

Desse ponto de vista, a novidade das ações de apoio e fomento à economia solidária reside na incubação de empreendimentos, realizada principalmente por universidades, segundo uma metodologia que se contrapõe, em vários pontos, ao modelo SEBRAE. Além das incubadoras universitárias, essa metodologia tem sido empregada por setores do movimento sindical e por ONGs, sendo bem provável que seus princípios fundamentais caracterizem há mais tempo a atuação de instituições antigas nesse campo, como a Cáritas, alguns órgãos de governo e cooperativas de técnicos. O fato de que esses segmentos de apoio estejam bem posicionados no tocante ao seu impacto sobre o desenvolvimento global dos EES (ao contrário do Sistema S), teria um princípio explicativo na sua identificação com esse novo modelo, designado como Tecnologias Sociais.

O termo evoca as ações de incubagem, formação e assessoramento técnico voltadas ao desenvolvimento de tecnologias de produção apropriadas aos empreendedores, mediante o acionamento do potencial representado por seus arranjos socioprodutivos, em razão dos saberes já acumulados e de seus recursos humanos e relacionais. A transferência da tecnologia científica articula-se com a reativação e reapropriação das tecnologias autóctones, voltadas à produção adaptada ao ambiente natural e à cultura local, com a finalidade explícita de melhorar a qualidade de vida da população, segundo uma ética de solidariedade (Lianza; Addor, 2005; Silva, 2008). As tecnologias sociais têm visado principalmente às experiências que buscam soluções coletivas por meio da auto-organização e da associação econômica. Ao adotarem o princípio de fortalecer a capacidade de ação dos empo- 
brecidos, essas experiências constituem um campo apropriado para a avaliação dos programas de ativação e de desenvolvimento do empreendedorismo popular associativo.

A modalidade mais abrangente de intervenção corresponde à incubagem, um processo de assessoria, formação e acompanhamento que se estende dos primeiros estágios até a estruturação jurídica e o funcionamento autônomo dos empreendimentos. Os instrumentos pedagógicos apropriados devem promover a participação dos beneficiários, valorizando sua cultura e seus saberes diante do conhecimento acadêmico Assim, os passos a dar na formação do futuro empreendimento refletiriam as demandas reais, fortaleceriam as capacidades existentes e garantiriam a agregação de novos conhecimentos pelos empreendedores. Objetivos também anunciados pelas ações do SEBRAE e pelas incubadoras de empresas, mas segundo outras premissas e métodos. Entre o linguajar comum e a semântica efetiva, situam-se precisamente as questões de pesquisa aqui apontadas.

A presença de entidades de apoio vinculadas ao Sistema S ou, por outro lado, às ONGs e universidades, é registrada pelos MPEA com uma frequência ligeiramente superior aos demais EES, o que mantém a pertinência de um estudo comparativo a respeito. Caberia, então, escrutinar os dados do SIES, com o objetivo de separar e analisar detidamente os MPEA sob influência direta de organizações claramente identificadas com as tecnologias sociais ou com o modelo SEBRAE. As tentativas realizadas com esse propósito esbarraram, todavia, em um obstáculo de ordem cronológica: as ações de apoio e fomento no campo das tecnologias sociais, vinculadas muitas vezes a programas públicos de fomento, são recentes e apenas estavam iniciando quando se realizou o Mapeamento. ${ }^{18}$ Elas se dirigiam a MPEA ainda em fase de implantação ou excessivamente novos para

${ }^{18}$ Mais de 60\% dos MPEA apoiados por ONGs ou por universidades iniciaram suas atividades a partir de 2001. As formas de apoio mais antigas provêm principalmente do movimento sindical e das cooperativas de técnicos (em cooperativismo) e, em seguida, de órgãos de governo e do Sistema S. sustentarem juízos consistentes sobre a eficiência das metodologias empregadas em seu favor, exceto talvez do ponto de vista dos critérios prévios utilizados pelas entidades para delimitarem o seu público-alvo. ${ }^{19}$

A segunda edição do Mapeamento, esperada em 2009, há de permitir que se dimensionem os focos e áreas de atuação das entidades de apoio, correlacionando a incidência dessas formas de atuação com as demandas principais dos MPEA atendidos, o seu perfil econômico e o seu grau de viabilidade. Com base em indicadores de desempenho dos MPEA, tornar-se-á possível mensurar a eficácia dos métodos empregados pelas tecnologias sociais. Outras questões a serem consideradas dizem respeito ao peso das externalidades e à assimetria de poder existente entre as organizações de apoio e os empreendimentos, em particular no caso das incubadoras que lidam com indivíduos minimamente organizados. São notórios os riscos de confinamento dos grupos populares na malha singular de relações tecidas pela organização de apoio, chave de acesso aos recursos externos, um problema já assinalado a propósito dos movimentos sociais pós-70 (Doimo, 1995). A pragmática econômica na qual se encontram os empreendedores pode ainda ser traída pela abordagem militante e voluntarista dos agentes mediadores, em franca contradição com os seus princípios de intervenção.

Esse rol de problemas demanda investigações qualitativas, integradas ao estudo aprofundado das bases de dados. ${ }^{20} \mathrm{Um}$ tema relevante, posto que a evolução dos EES supõe quase invariavelmente o apoio e acompanhamento de uma ou mais organizações. As formas como atuam junto aos grupos populares constituem um patrimônio me-

${ }^{19}$ Os principais órgãos públicos de fomento às tecnologias sociais têm sido o Banco do Brasil e a FINEP. A oferta crescente de recursos provocou uma rápida adesão das entidades de apoio, restando saber em que medida houve uma efetiva adoção dos novos objetivos e métodos propostos.

${ }^{20}$ Um dos estudos valiosos sobre o tema foi concluído em 2007: Incubação de empreendimentos da economia solidária e as implicações nas relações de reciprocidade, de Rosana Kirsch (apresentado como Dissertação de Mestrado em Sociologia, na Universidade de Brasília). 
recedor de maior conhecimento, sobretudo à medida que tais métodos, singulares na sua concepção original, possam vencer bloqueios e favorecer o trânsito do ator popular em diferentes esferas e formas de interlocução. Propiciar vias de conexão entre diferentes modelos, antes do que a universalização de uma alternativa única, parece ser o melhor caminho para que a economia solidária ofereça respostas a distintas demandas, de natureza econômica, de direitos e de cidadania.

A contribuição preliminar deste estudo reside em articular teoricamente a problemática das desigualdades às políticas redistributivas que incorporam a diretiva de fortalecimento do protagonismo econômico dos pobres como linha primordial, reconhecendo o seu potencial produtivo. A discussão do modelo preponderante nesse campo, assente nos aspectos individuais e utilitários da conduta econômica, revelou suas inadequações às características apresentadas pelos setores populares, abrindo espaço para uma abordagem alternativa, calcada na ativação dos recursos relacionais e nas práticas e possibilidades associativas dos pequenos empreendedores. Os dados do primeiro Mapeamento Nacional da Economia Solidária indicam a presença de um padrão de empreendedorismo associativo e referendam essa linha investigativa, quer sobre as condições prévias para que se institua, quer sobre suas variantes ou sobre as modalidades de apoio mais propícias ao seu desenvolvimento, em favor da maior equidade econômica e social.

(Recebido para publicação em janeiro de 2009) (Aceito em junho de 2009)

\section{REFERÊNCIAS}

ABRAMOVAY, Ricardo (Org.) Laços financeiros na luta contra a pobreza. São Paulo: Annablume, 2004. et al. Mercados do empreendedorismo de pequeno porte. Brasília,DF: CEPAL, 2003.

BARROS, Ricardo et al. A importância da queda recente da desigualdade para a pobreza. In: FOGUEL Miguel; ULYSSEA, Gabriel (Org.). Desigualdade de renda no Brasil: uma análise da queda recente. Rio de Janeiro: IPEA, 2007. p.331-353.
BOUTILLIER, Sophie; UZUNIDIS, Dimitri. La légende de l'entrepreneur. Le capital social ou comment vient l'esprit d'entreprise. Paris: Syros, 1999.

CATTANI, Antônio. Desigualdades socioeconômicas: conceitos e problemas de pesquisa. Sociologias, Porto Alegre, v.9, n.18, p.74-98, 2008.

CORAGGIO, José. Da economia dos setores populares à economia do trabalho: In: KRAYCHETE, Gabriel; LARA,

Francisco; COSTA, Beatriz (Org.) Economia dos setores populares: entre a realidade e a utopia. Petrópolis: Vozes, 2000. p.91-132.

(Org.). La economía social desde la periferia. Contribuciones latinoamericanas. Buenos Aires: UNGSAltamira, 2007.

DEJOURS, Christophe. A banalização da injustiça social. 7.ed. Rio de Janeiro: Fundação Getúlio Vargas, 2007.

DOIMO, Ana. A vez e a voz do popular. Rio de Janeiro: Relume-Dumará, 1995.

FERRÃO, Paulo et al. (Org.) Inovação, empreendedorismo e desenvolvimento. Preparar Portugal para um novo ciclo de fundos estruturais 2007 - 2013. Lisboa: Centro de Estudos em Inovação, Tecnologia e Políticas de Desenvolvimento, 2005. (Estudo apresentado ao Observatório do QCA III)

GAIGER, Luiz (Org.) Sentidos e experiências da economia solidária no Brasil. Porto Alegre: Editora da UFRGS, 2004a.

A economia solidária e o projeto de outra mundialização. DADOS: revista de ciências sociais, Rio de Janeiro, v.47, n.4, p.799-834, 2004b.

Economie solidaire et espace public; quelques remarques à propos du rôle des agents médiateurs. In LAVILLE, Jean-Louis et al. (Org.) Action publique et économie solidaire : une perspective internationale. Ramonville Saint-Agne: Editons Erès, 2005. p.321-334.

A racionalidade dos formatos produtivos autogestionários. Sociedade e Estado, Brasília, v.21, n.2, p.513-545, 2006

A outra racionalidade da economia solidária. Conclusóes do Primeiro Mapeamento Nacional no Brasil. Revista Crítica de Ciências Sociais, Coimbra, Centro de Estudos Sociais, n.79, p. 57-77, 2007.

; ASSEBURG, Benno. A economia solidária diante das desigualdades. DADOS: revista de ciências sociais, Rio de Janeiro, v.50, n.3, p.499-533, 2007.

: LAVILLE, Jean-Louis. Economia solidária. In: GAIGER, Luiz et al. (Org.) Dicionário internacional da outra economia. Coimbra: Almedina, 2009. p.162-168.

HESPANHA, Pedro. The activation trend in the portuguese social policy: un open process? In: CONGRESSO ACTIVATION POLICIES AND THE LABOUR MARKET REGIMES. Bruxelas: European Trade Union Institute, 2005.

KIRSCHNER, Ana. A sociologia e a empresa. Revista Brasileira de Informação Bibliográfica em Ciências Sociais, São Paulo, n.55, p.99-121, 2003.

KLIKSBERG, Bernardo. Desigualdade na América Latina: o debate adiado. 3.ed. São Paulo: Cortez; Brasília: UNESCO, 2002.

KRAYCHETE, Gabriel. Economia dos setores populares: entre a realidade a utopia. In: ; LARA, Francisco; COSTA, Beatriz (Org.). Economia dos setores populares: entre a realidade e a utopia. Petrópolis: Vozes, 2000. p.15-37.

LAUTIER, Bruno. Économie informelle. In: LAVILLE, Jean-Louis ; CATTANI, Antonio (Org.). Dictionnaire de 
l'autre économie. Paris: Desclée de Brouwer, 2005. p.175182.

LAVILLE, Jean-Louis et al. (Org.) Action publique et économie solidaire: une perspective internationale. Ramonville Saint-Agne: Editons Erès, 2005.

LIANZA, Sidney; ADDOR, Felipe (Org.) Tecnologia e desenvolvimento social e solidário. Porto Alegre: UFRGS, 2005.

LIMA, Jacob. O trabalho autogestionário em cooperativas de produção; o paradigma revisitado. Revista Brasileira de Ciências Sociais, São Paulo, v.29, n.56, p.45-62, 2004.

MARTINS, Paulo; MEDEIROS, Alzira (Org.) Economia popular e solidária: desafios teóricos e práticos. Recife: Edições Bagaço, 2003.

MEDEIROS, Marcelo. O que faz os ricos ricos: o outro lado da desigualdade brasileira. São Paulo: Hucitec ANPOCS, 2005.

NERI, Marcelo. A Dinâmica da distribuição trabalhista. In: BARROS, Ricardo; FOGUEL, Miguel; ULYSSEA, Gabriel (Org.) Desigualdade de renda no Brasil: uma análise da queda recente. Rio de Janeiro: IPEA, 2007. p.207235.

PASSOS, Carlos et al. Empreendedorismo no Brasil 2007. Curitiba: IBPQ, 2008.

PEIXOTO, José; LOPES, Vera. A reestruturação produtiva no Brasil e o caso das empresas industriais sob regime de autogestão ou co-gestão. Rio de Janeiro: COPPE-UFRJ, 1999.

PICCININI, Valmíria. Cooperativas de trabalho de Porto Alegre e flexibilização do trabalho. Sociologias, Porto Alegre, v.6, n.12, p.68-104, 2004.

PORTELA, José et al. Microempreendedorismo em Portugal: experiências e perspectivas. Lisboa: INSCOOP/GRECA Artes Gráficas, 2008.
PUTNAM, Robert. Comunidade e democracia: a experiência da Itália moderna. Rio de Janeiro: Fundação Getúlio Vargas, 1996.

RAZETO, Luis. Los caminos de la economía de solidaridad. Buenos Aires: Editorial Lumen-Hvmanitas, 1997

SALES, Teresa. Raízes da desigualdade social na cultura política brasileira. Revista Brasileira de Ciências Sociais, São Paulo, v.25, n.9, p.26-37, 1994.

SALM, Cláudio. Sobre a recente queda da desigualdade de renda no Brasil: uma leitura crítica. In: BARROS, Ricardo FOGUEL, Miguel; ULYSSEA, Gabriel (Org.) Desigualdade de renda no Brasil: uma análise da queda recente. Rio de Janeiro: IPEA, 2007. p.279-297.

SAINSAULIEU, Renaud; KIRSCHNER, Ana. Sociologia da empresa: cultura, poder, organização e desenvolvimento. Rio de Janeiro: DP\&A, 2006.

SANTOS, Boaventura (Org.) Produzir para viver: os caminhos da produção não-capitalista. Rio de Janeiro: Civilização Brasileira, 2002.

SEN, Amartya. L'économie est une science morale. Paris: La Découverte, 1999. 2001

Desigualdade reexaminada. Rio de Janeiro: Record,

SILVA, Roberto. Entre o combate à seca e a convivência com o semi-árido: transições paradigmáticas e sustentabilidade do desenvolvimento. Fortaleza: Banco do Nordeste, 2008.

SINGER, Paul. Globalização e desemprego: diagnóstico e alternativas. 3.ed. São Paulo: Contexto, 1999.

; SOUZA, André (Org.) A economia solidária no Brasil: a autogestão como resposta ao desemprego. São Paulo: Contexto, 2000. 


\section{THE ECONOMICAL ASSOCIATION OF THE POOR AS A WAY OF FIGHTING INEQUALITIES}

\section{Luiz Inácio Germany Gaiger}

This paper retakes the debate on the ways of resolution of inequalities, sustaining that the initiatives with that end need to seek the economical activation of the underprivileged sectors, the most suitable way to generate equality and development.

It proceeds to examines the predominant model of activation, addressed to the development of the individual competences, in which it points inadequacies. It opposes a second model, of promotion of the associative enterprisism and, starting from the data of first National Mapping of the Solidary Economy in Brazil, it identifies a reference pattern correlated. Its analysis leads to a preliminary swinging of the preservation and consolidation of economical agents' possibilities linked to the productive cooperation and in selfmanagement.

KEYwORDS: cooperation, solidary economy, enterprisism, poverty, social technologies.

\section{L'ASSOCIATION ECONOMIQUE DES PAUVRES COMME MOYEN POUR COMBATTRE LES INEGALITES}

\section{Luiz Inácio Germany Gaiger}

Ce travail reprend le débat concernant les inégalités et les alternatives existantes pour les résoudre. On y affirme que les initiatives prises dans ce sens doivent envisager l'activation économique des secteurs défavorisés car ceci semble être la manière la plus favorable à un développement équitable. On examine ensuite le modèle dominant de l'activation, qui vise le développement de compétences individuelles, et où on souligne ses insuffisances et ses lacunes. Un autre modèle s'y oppose, celui de la promotion de l'entreprenariat selon des modèles associatifs et, à partir des données du premier Relevé National de l'Economie Solidaire au Brésil, on identifie un modèle de référence corrélatif. L’analyse qui a été faite permet d'établir un premier bilan des possibilités de préservation et de consolidation des agents économiques marqués par la coopération productive et l'autogestion.

MoTS-CLÉs: coopération, économie solidaire, esprit d'entreprise, pauvreté, technologies sociales.

Luiz Inácio Germany Gaiger - Doutor em Sociologia e pesquisador do CNPq desde 1999. Professor titular I da Universidade do Vale do Rio dos Sinos. Coordenador do Programa de Pós-Graduação em Ciências Sociais da Universidade do Vale do Rio dos Sinos - Unisinos. Coordenador do Grupo de Pesquisa em Economia Solidária (www.ecosol.org.br) e da Cátedra Unesco - Unisinos Trabalho e Sociedade Solidária. Última publicação: GAIGER, Luiz; CATTANI, Antonio; HESPANHA, Pedro; LAVILLE, Jean-Louis (Org.). Dicionário internacional da outra economia. Coimbra: Almedina, 2009. 